\title{
ANALISA METODE WEIGHTED SUM MODEL (WSM) PENERIMA KARTU INDONESIA PINTAR (KIP) KEPADA SISWA/I DI SD (SEKOLAH DASAR)
}

\section{Marlina Drawati Saragih"1, Heru Satria Tambunan², Rafiqa Dewi ${ }^{3}$}

${ }^{1}$ Mahasiswa STIKOM Tunas Bangsa, Pematangsiantar, Indonesia

${ }^{2}$ Dosen STIKOM Tunas Bangsa Pematangsiantar, Indonesia

Email: ${ }^{1}$ marlinadrawatisaragih@gmail.com, ${ }^{2}$ heru@amiktunasbangsa.ac.id, ${ }^{3}$ rafiqa@ amiktunasbangsa.ac.id

\begin{abstract}
Abstrak
Kartu Indonesia Pintar merupakan bantuan berupa uang tunai dari pemerintah yang diberikan kepada peserta didik yang orangtuanya kurang mampu membiayai pendidikannya. Sebagai kelanjutan dan perluasan sasaran dari program Bantuan Siswa Miskin (BSM). KIP mempunyai tujuan yaitu meningkatkan akses bagi anak usia 6 (enam) sampai 21 (duapuluh satu tahun). Pada Sekolah Dasar 091329 didalam penerima Kartu Indonesia Pintar menghadapi banyak masalah Seperti siswa/i yang berhak menerima bantuan sebenarnya jadi tidak menerima. karena itu terjadilah protes dan demonstrasi yang disebabkan Kartu Indonesia Pintar yang tidak tepat sasaran. Adapun kriteria dari penerima kartu Indonesia pintar pemegang kartu perlindungan sosial, penghasilan orangtua, tidak mempunyai kenderaan, jumlah tanggungan, anak yatim/piatu. Pada penerapannya tentu memiliki kendala kendala dalam memutuskan siapa siswa yang mendapatkan kartu Indonesia pintar tersebut. Untuk menyelesaikan permasalaan di butuhkan sebuah sistem pendukung keputusan dengan metode Weighted Sum Model (WSM) dapat mengatasi permasalahan ini. Dengan menerapkan Weighted Sum Model (WSM) yang tergolong mudah dan cepat, diyakini mampu mendapatkan hasil yang terbaik. Penelitian ini dapat memberikan informasi kepada pihak sekolah dalam penerima Kartu Indonesia Pintar(KIP) untuk tahun berikutnya.
\end{abstract}

Kata kunci: SPK, Weighted Sum Model (WSM), Penerima Kartu Indonesia Pintar

\begin{abstract}
Indonesia Smart Card is a cash assistance from the government given to students whose parents are less able to finance their education. As a continuation and expansion of the objectives of the Poor Student Assistance (BSM) program. KIP has the goal of increasing access for children aged 6 (six) to 21 (twenty one years). In Primary School 091329 in the recipient of the Smart Indonesia Card faces many problems As students who are entitled to receive assistance actually do not receive. because of that there were protests and demonstrations caused by Kartu Indonesia Pintar which were not on target. The criteria for Indonesian card recipients are smart social protection card holders, parents' income, no vehicles, no dependents, orphans. In its implementation, it certainly has obstacles in deciding who students get the smart Indonesian card. To solve the problem, a weighted Sum Model (WSM) decision support system can overcome this problem. By applying the Weighted Sum Model (WSM) which is relatively easy and fast, it is believed to be able to get the best results. This research can provide information to the school in the recipient of the Indonesia Smart Card (KIP) for the following year.
\end{abstract}

Keywords: SPK, Weighted Sum Model (WSM), Receiver of Smart Indonesia Cards

\section{PENDAHULUAN}

Pada saat ini perkembangan teknologi sangat tumbuh dengan pesat, baik dibidang teknologi telekomunikasi sampai dengan teknologi komputasi. Dalam bidang komputer sendiri banyak hal yang tumbuh dan berkembang dahulu komputer hanya dapat digunakan untuk pengumpulan dan pengolahan data namun sekarang komputer juga dapat dijadikan sebagai alat untuk membantu membuat suatu keputusan [1]. Sistem Pendukung Keputusan merupakan bagian dari sistem informasi berbasis komputer yang dipakai untuk mendukung pengambilan keputusan dalam suatu masalah. Pada Sekolah Dasar (SD) di dalam eksekusi dari penerima Kartu Indonesia Pintar terhadap siswa/i kurang mampu ini menghadapi banyak masalah Seperti siswa/i yang berhak menerima bantuan sebenarnya jadi tidak menerima oleh karena itu terjadilah protes dan demonstrasi yang disebabkan Kartu Indonesia Pintar yang tidak tepat sasaran. Dengan mengacu pada masalah yang ada maka tujuan yang hendak dicapai dalam penelitian ini adalah menghasilkan Sistem Pendukung Keputusan Peneriman Kartu Indonesia pintar bagi siswa/i SD Negeri 091329 yang kurang Mampu. Proses penilaian diserahkan kepada kepala sekolah yang bersifat subyektif. Hal ini dikhawatirkan menimbulkan suatu kecurangan dan ketidaktepatan dalam menilai sehingga tidak sampai kepada siswa/i kurang mampu yang benar-benar membutuhkan.Penelitian terdahulu "Penerapan Weighted Sum Model (WSM) Dalam Penentuan Peserta Jaminan Kesehatan Masyarakat [2]. Karena saat ini banyak Jamkesmas yang dinilai tidak tepat sasaran, dimana masih banyak orang yang seharusnya berhak, justru tidak mendapatkan jamkesmas tersebut, begitu juga sebaliknya. Hal ini berdampak adanya subjektifitas di dalam penentuan peserta Jamkesmas, terutama jika beberapa calon peserta yang ada memiliki tingkat kelayakan yang tidak jauh berbeda. disimpulkan bahwa metode Weighted Sum Model (WSM) salah satu dari MCDM yang sangat sederhana penerapannya yang dapat membantu pengambil keputusan menghasilkan suatu keputusan yang terbaik dari beberapa alternatif. Penerapan Weighted Sum Model (WSM) tidak membedakan kriteria benefit ataupun cost, sehingga bobot sangat mempengaruhi perhitungan hasil yang terbaik.Dalam penelitian ini metode yang digunakan adalah metode Weighted Sum Model (WSM) merupakan metode yang sangat umum, dan banyak diterapkan untuk membantu pengambil keputusan dalam 
mengambil suatu keputusan. Weighted Sum Model (WSM) merupakan salah satu metode yang paling sederhana dan mudah dipahami penerapannya. Metode yang sering digunakan pada permasalahan dimensi tunggal Merupakan bagian dalam metode MCDM (Multi-Criteria Decison Making) [2].

\section{METODE PENELITIAN}

Adalah proses atau cara ilmiah untuk mengumpulkan data yang akan digunakan untuk keperluan penelitian. Metodologi yang digunakan untuk menyelesaikan masalah - masalah penelitian.

\subsubsection{Metode Pengumpulan Data}

Merupakan teknik atau cara yang dilakukan oleh peneliti untuk mengumpulkan data. Pengumpulan data dilakukan untuk memperoleh informasi yang dibutuhkan dalam rangka mencapai tujuan penelitian.

1. Penelitian Kepustakaan (Library Reserch) yaitu memanfaatkan perpustakaan sebagai sarana dalam mengumpulkan data dengan mempelajari buku - buku sebagai bahan referensi.

2. Penelitian lapangan (Filed Work Research) yaitu penelitian yang dilakukan secara langsung dilapangan dengan menggunakan beberapa teknik sebagai berikut :

a. Observasi adalah metode pengumpulan data dengan cara mengadakan pengamatan langsung terhadap berbagai kegiatan yang ada.

b. Wawancara adalah proses pengumpulan data atau informasi melalui tatap muka antara pihak penanya (interviewer) dengan pihak yang ditanyai atau penjawab (interview).

\subsubsection{Analisa Permasalahan}

Berdasarkan hasil analisa yang dilakukan penulis dapat disimpulkan bahwa permasalahan yang menjadi dasar dilakukanya penelitian ini adalah belum maksimalnya penyeleksian dalam penerima Kartu Indonesia Pintar terhadap siswa/i. untuk mengatasi yang masalah tersebut dibutuhkan suatu teknologi komputer dengan analisa metode Weighted Sum Model (WSM).

\subsection{Weighted Sum Model (WSM)}

Metode Metode Weighted Sum Model merupakan metode yang sangat umum, dan banyak diterapkan untuk membantu pengambil keputusan dalam mengambil suatu keputusan. Weighted Sum Model (WSM) merupakan salah satu metode yang paling sederhana dan mudah dipahami penerapannya [2]. Weighted Sum Model (WSM) adalah model umum, telah digunakan untuk aplikasi yang berbeda seperti robotika, processor dan lain-lain [1].

\subsection{Kartu Indonesia Pintar (KIP)}

Kartu Indonesia Pintar (KIP) Program Indonesia Pintar melalui KIP adalah pemberian bantuan tunai pendidikan kepada seluruh anak usia sekolah (6-21 tahun) yang menerima KIP, atau yang berasal dari keluarga miskin dan rentan (misalnya dari keluarga/rumah tangga pemegang Kartu Keluarga Sejahtera/KKS) atau anak yang memenuhi kriteria yang telah ditetapkan sebelumnya. Program Indonesia Pintar melalui KIP merupakan bagian penyempurnaan dari Program Bantuan Siswa Miskin (BSM) sejak akhir 2014.[3]

\section{HASIL DAN PEMBAHASAN}

\subsection{Praprocessing Data}

Sebelum memasuki tahap perhitungan menggunakan algoritma Weinghthed Sum Model (WSM), penulis terlebih dahulu melakukan preprocessing data yaitu dengan menentukan kriteria-kriteria yang akan dijadikan acuan dalam pengambilan keputusan dan memberikan bobot penilaian untuk setiap kriteria. Berdasarkan data yang diperoleh dari hasil wawancara dan studi pustaka didapatkan data kriteria seperti yang terlihat pada tabel 1

Tabel 1. Tabel Kriteria

\begin{tabular}{lll}
\hline Kriteria & Keterangan & Bobot \\
\hline C1 & Pemegang KPS & $20 \%$ \\
C2 & Pekerjaan orangtua & $15 \%$ \\
C3 & Penghasilan orangtua & $15 \%$ \\
C4 & Jumlah tanggungan & $15 \%$ \\
C5 & Status anak & $5 \%$ \\
C6 & Rumah layak huni & $10 \%$ \\
C7 & Dampak bencana alam & $10 \%$ \\
C8 & Tinggal dipanti asuhan & $10 \%$ \\
\hline
\end{tabular}


Dari data kriteria dan pembobotan dari table diatas, penulis melakukan penyusunan kriteria berdasarkan nilai perioitas mulai dari kriteria dengan nilai bobot terendah hingga kriteria dengan nilai bobot tertinggi. Penentuan bobot berdasarkan dari lima bilangan fuzzy yaitu, sangat rendah (SR), rendah (R), cukup ( C), tinggi (T), dan sangat tinggi (ST) seperti terlihat pada tabel

Tabel 2. Tabel Bobot

\begin{tabular}{lc}
\hline \multicolumn{1}{c}{ Bilangan Fuzzy } & Nilai \\
\hline Sangat Rendah & 0,15 \\
Rendah & 0,17 \\
Cukup & 0,20 \\
Tinggi & 0,23 \\
Sangat Tinggi & 0,25 \\
\hline
\end{tabular}

Tabel 3. Tabel Penjabaran Kriteria dari Bobot

\begin{tabular}{clc}
\hline Kriteria & \multicolumn{1}{c}{ Keterangan } & Bobot \\
\hline \multirow{2}{*}{ C1 } & Pemegang & 0,25 \\
& Tidak Pemegang & 0,17 \\
& Bertani 2 & 0,23 \\
& Wiraswasta & 0,20 \\
& PNS & 0,17 \\
C3 & Rp.500.000 s/d 1000.000 & 0,23 \\
& Rp.1.100.000 s/d 1.500.000 & 0,20 \\
& Rp.2000.000 & 0,17 \\
C4 & 1 atau 2 Anak & 0,17 \\
& Lebih dari 4 anak & 0,20 \\
& Yatim & 0,23 \\
C5 & Piatu & 0,20 \\
& Yatim/piatu & 0,20 \\
& Masih Hidup & 0,23 \\
& Dinding Bambu dan Lantai Tanah & 0,17 \\
C6 & Dinding Papan dan Lantai Tanah & 0,25 \\
& Dinding Papan dan Lantai Semen & 0,23 \\
& Dinding Beton dan Lantai Keramik & 0,20 \\
& Cacat Terkena Longsor & 0,17 \\
\multirow{2}{*}{ C7 } & Cacat Terkena Banjir & 0,20 \\
& Cacat Kebakaran & 0,20 \\
& Tidak Sama Sekali & 0,20 \\
& Tidak tinggal di pantiasuhan & 0,17 \\
& Tinggal di pantiasuhan & 0,23 \\
& & 0,17 \\
\hline
\end{tabular}

Tabel 4. Tabel KPS

\begin{tabular}{ccc}
\hline Pemegang KPS & Keterangan & Nilai \\
\hline Pemegang & Sangat tinggi & 0,25 \\
Tidak Pemegang & Redah & 0,17 \\
\hline
\end{tabular}

Tabel 5. Tabel Pekerjaan Orangtua

\begin{tabular}{ccc}
\hline Pekerjaan Orangtua & Keterangan & Nilai \\
\hline Bertani & Tinggi & 0,23 \\
Wiraswasta & Cukup & 0,20 \\
PNS & Rendah & 0,17 \\
\hline
\end{tabular}

Tabel 6. Tabel Penghasilan Orangtua

\begin{tabular}{lcc}
\hline \multicolumn{1}{c}{ Penghasilan Orangtua } & Keterangan & Nilai \\
\hline Rp.500.000 s/d 1000.000 & Tinggi & 0,23 \\
Rp.1.100.000 s/d 1.500 .000 & Cukup & 0,20
\end{tabular}




\begin{tabular}{lcc} 
Rp.2000.000 & \multicolumn{3}{c}{ Rendah } \\
\cline { 2 - 3 } & \multicolumn{3}{c}{ Tabel 7. Tabel Jumlah Tanggungan } \\
Jumlah Tanggungan & Keterangan & Nilai \\
& & \\
\hline 1 atau 2 Anak & Rendah & 0,17 \\
3 atau 4 anak & Cukup & 0,20 \\
Lebih dari 4 anak & Tinggi & 0,23 \\
\hline
\end{tabular}

Tabel 8. Tabel Status Anak

\begin{tabular}{ccc}
\hline Status Anak & Ket & Nilai \\
\hline Yatim & Cukup & 0,20 \\
Piatu & Cukup & 0,20 \\
Yatim/piatu & Tinggi & 0,23 \\
Masih Hidup & Rendah & 0,17 \\
\hline
\end{tabular}

Tabel 9. Tabel Rumah Layak Huni (Keadaan Rumah)

\begin{tabular}{lcc}
\hline \multicolumn{1}{c}{ Rumah layak huni (Keadaan Rumah) } & Keterangan & Nilai \\
\hline Dinding Bambu dan Lantai Tanah & Sangat Tinggi & 0,25 \\
Dinding Papan dan Lantai Tanah & Tinggi & 0,23 \\
Dinding Papan dan Lantai Semen & Cukup & 0,20 \\
Dinding Beton dan Lantai Keramik & Rendah & 0,17 \\
\hline
\end{tabular}

Tabel 10. Tabel Dampak Bencana Alam

\begin{tabular}{ccc}
\hline Dampak bencana alam & Keterangan & Nilai \\
\hline Cacat Terkena Longsor & Cukup & 0,20 \\
Cacat Terkena Banjir & Cukup & 0,20 \\
Cacat Kebakaran & Cukup & 0,20 \\
Tidak Sama Sekali & Rendah & 0,17 \\
\hline
\end{tabular}

Tabel 11. Tabel Tinggal di Panti Asuhan

\begin{tabular}{ccc}
\hline Tinggal di Panti Asuhan & Keterangan & Nilai \\
\hline Tidak tinggal di pantiasuhan & Tinggi & 0,23 \\
Tinggal di pantiasuhan & Rendah & 0,17 \\
\hline
\end{tabular}

Pada tabel dibawah ini menunjukan 30 data alternatif dari 30 orang siswa yang layak mendapatkan Kertu Indonesia Pintar yang akan memenuhi persyaratan kelayakan mendapatkan Kartu Indonesia Pintar pada SD Negeri 091329 adalah sebagai berikut.

Tabel 12. Menentukan Rating Kecocokan Setiap Alternative Pada Setiap Kriteria

\begin{tabular}{ccccccccc}
\hline Alteratif & C1 & C2 & C3 & C4 & C5 & C6 & C7 & C8 \\
\hline A1 & 0,25 & 0,23 & 0,23 & 0,20 & 0,17 & 0,20 & 0,17 & 0,17 \\
A2 & 0,25 & 0,23 & 0,20 & 0,20 & 0,17 & 0,20 & 0,17 & 0,17 \\
A3 & 0,25 & 0,23 & 0,23 & 0,23 & 0,17 & 0,20 & 0,17 & 0,17 \\
A4 & 0,25 & 0,23 & 0,20 & 0,17 & 0,17 & 0,20 & 0,17 & 0,17 \\
A5 & 0,25 & 0,23 & 0,20 & 0,20 & 0,17 & 0,20 & 0,17 & 0,17 \\
A6 & 0,25 & 0,23 & 0,20 & 0,20 & 0,17 & 0,20 & 0,17 & 0,17 \\
A7 & 0,25 & 0,23 & 0,20 & 0,20 & 0,17 & 0,20 & 0,17 & 0,17 \\
A8 & 0,25 & 0,23 & 0,23 & 0,20 & 0,17 & 0,20 & 0,17 & 0,17 \\
A9 & 0,25 & 0,23 & 0,23 & 0,20 & 0,17 & 0,20 & 0,17 & 0,17 \\
A10 & 0,25 & 0,23 & 0,20 & 0,20 & 0,17 & 0,20 & 0,17 & 0,17 \\
A11 & 0,25 & 0,23 & 0,20 & 0,20 & 0,17 & 0,20 & 0,17 & 0,17 \\
A12 & 0,25 & 0,23 & 0,23 & 0,20 & 0,17 & 0,20 & 0,17 & 0,17 \\
A13 & 0,25 & 0,23 & 0,23 & 0,23 & 0,17 & 0,20 & 0,17 & 0,17 \\
A14 & 0,25 & 0,23 & 0,20 & 0,17 & 0,17 & 0,20 & 0,17 & 0,17 \\
A15 & 0,25 & 0,23 & 0,23 & 0,23 & 0,17 & 0,20 & 0,17 & 0,17 \\
A16 & 0,25 & 0,23 & 0,23 & 0,20 & 0,17 & 0,17 & 0,17 & 0,17
\end{tabular}




\begin{tabular}{lllllllll} 
A17 & 0,25 & 0,23 & 0,23 & 0,23 & 0,17 & 0,20 & 0,17 & 0,17 \\
A18 & 0,25 & 0,23 & 0,23 & 0,20 & 0,17 & 0,20 & 0,17 & 0,17 \\
A19 & 0,25 & 0,23 & 0,23 & 0,20 & 0,17 & 0,20 & 0,17 & 0,17 \\
A20 & 0,25 & 0,23 & 0,23 & 0,23 & 0,17 & 0,17 & 0,17 & 0,17 \\
A21 & 0,25 & 0,23 & 0,23 & 0,20 & 0,17 & 0,20 & 0,17 & 0,17 \\
A22 & 0,25 & 0,23 & 0,23 & 0,20 & 0,17 & 0,20 & 0,17 & 0,17 \\
A23 & 0,25 & 0,23 & 0,23 & 0,20 & 0,17 & 0,20 & 0,17 & 0,17 \\
A24 & 0,25 & 0,23 & 0,23 & 0,17 & 0,23 & 0,20 & 0,17 & 0,17 \\
A25 & 0,25 & 0,23 & 0,23 & 0,20 & 0,17 & 0,20 & 0,17 & 0,17 \\
A26 & 0,25 & 0,23 & 0,20 & 0,20 & 0,17 & 0,17 & 0,17 & 0,17 \\
A27 & 0,25 & 0,23 & 0,20 & 0,20 & 0,17 & 0,20 & 0,17 & 0,17 \\
A28 & 0,25 & 0,23 & 0,20 & 0,20 & 0,17 & 0,20 & 0,17 & 0,17 \\
A29 & 0,25 & 0,23 & 0,20 & 0,20 & 0,17 & 0,20 & 0,17 & 0,17 \\
A30 & 0,25 & 0,23 & 0,20 & 0,20 & 0,17 & 0,20 & 0,17 & 0,17 \\
\hline
\end{tabular}

Table diatas menunjukan rating kecocokan dari setiap alternatif pada setiap kriteria. Karena setiap nilai yang diberikan pada setiap alternatif disetiap kriteria merupakan nilai kecocokoan dimana niai terbesar adalah nilai terbaik. Untuk bobot sebagai berikut :

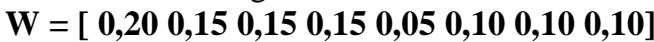

Berdasarkan Rumus maka perhitungan dari Weighted Sum Model (WSM) sebagai berikut:

$$
\begin{aligned}
\mathbf{A 1} & =(0,20 * 0,25)+(0,15 * 0,23)+(0,15 * 0,23)+(0,15 * 0,20)+(0,05 * 0,17)+(0,10 * 0,20)+(0,10 * 0,17)+(0,10 * 0,17) \\
& =\mathbf{0 , 2 1 1 5} \\
\mathbf{A 2} & (0,20 * 0,25)+(0,15 * 0,23)+(0,15 * 0,20)+(0,15 * 0,20)+(0,05 * 0,17)+(0,10 * 0,20)+(0,10 * 0,17)+(0,10 * 0,17) \\
& =\mathbf{0 , 2 0 7}
\end{aligned}
$$

\begin{tabular}{|c|c|c|}
\hline Alternatif & Nilai $W S M$ & Layak/Tidak layak \\
\hline A1 & 0,2115 & Layak \\
\hline $\mathrm{A} 2$ & 0,207 & Tidak layak \\
\hline A3 & 0,216 & Layak \\
\hline A4 & 0,2025 & Tidak layak \\
\hline A5 & 0,207 & Tidak layak \\
\hline A6 & 0,207 & Tidak layak \\
\hline A7 & 0,207 & Tidak layak \\
\hline A8 & 0,2115 & Layak \\
\hline A9 & 0,2115 & Layak \\
\hline A10 & 0,207 & Tidak layak \\
\hline A11 & 0,207 & Tidak layak \\
\hline A12 & 0,2115 & Layak \\
\hline A13 & 0,216 & Layak \\
\hline A14 & 0,205 & Tidak layak \\
\hline A15 & 0,216 & Layak \\
\hline A16 & 0,213 & Layak \\
\hline A17 & 0,216 & Layak \\
\hline A18 & 0,2115 & Layak \\
\hline A19 & 0,2115 & Layak \\
\hline A20 & 0,213 & Layak \\
\hline A21 & 0,2115 & Layak \\
\hline A22 & 0,2115 & Layak \\
\hline A23 & 0,2115 & Layak \\
\hline A24 & $\mathbf{0 , 2 1}$ & Layak \\
\hline A25 & 0,2115 & Layak \\
\hline A26 & 0,204 & Tidak layak \\
\hline $\mathrm{A} 27$ & 0,207 & Tidak layak \\
\hline A 28 & 0,207 & Tidak layak \\
\hline A29 & 0,207 & Tidak layak \\
\hline A30 & 0,207 & Tidak layak \\
\hline
\end{tabular}

Tabel 13. Hasil perengkingan

Berdasarkan hasil perengkingan pada tabel 14 diatas dengan metode weighted sum model dapat menentukan siswa penerima kartu Indonesia pintar (KIP) di SD Negeri 091329 Bahpasunsang perhitungan alternatif diatas maka 
dapat disimpulkan dari alternatif 30 siswa yang layak untuk mendapatkan kartu Indonesia pintar adalah A17 =0,216 ,A $13=0,216, \mathrm{~A} 15=0,216, \mathrm{~A} 3=0,216, \mathrm{~A} 16=0,213, \mathrm{~A} 20=0,213, \mathrm{~A} 8=0,2115, \mathrm{~A} 1=0,2115, \mathrm{~A} 12=0,2115, \mathrm{~A} 25$ $=0,2115, \mathrm{~A} 9=0,2115, \mathrm{~A} 21=0,2115, \mathrm{~A} 23=0,2115, \mathrm{~A} 19=0,2115, \mathrm{~A} 22=0,2115, \mathrm{~A} 18=0,2115, \mathrm{~A} 24=0,21$

\subsection{Hasil}

Dari penelitian yang dilakukan setelah proses menjelaskan tentang metode penelitian, maka hasil yang di peroleh akan ditampilkan berupa layout dari sistem pendukung keputusan yang telah di rancang. Adapun hasil implementasi dari sistem pendukung keputusan menentukan siswa penerima kartu indonesia pintar pada SD Negeri 091329 menggunakan metode Weighted Sum Model (WSM) sebagai berikut :

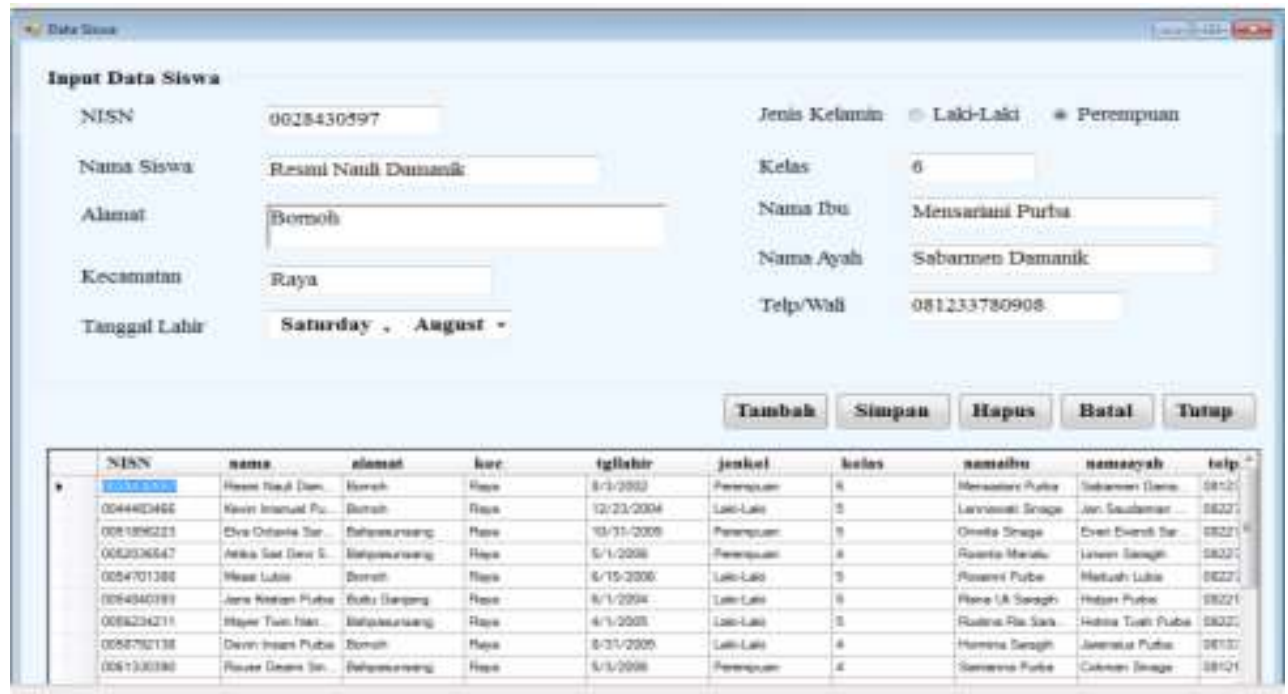

Gambar 1. Menu Hasil

\subsection{Pembahasan}

Setelah rancangan program selesai dilakukan uji sistem sebelum dilaksanakannya implementasi sistem untuk melihat apakah hasil program telah sesuai atau tidak dengan yang diharapkan. Proses yang dirancang dilakukan uji sistem dengan teknis statis, dimana telah dilakukan uji coba sistem untuk perangkat keras dan perangkat lunak yang dibutuhkan untuk menjalankan program beserta test running program.

\section{KESIMPULAN}

Berdasarkan hasil penelitian dan analisa yang telah dilakukan oleh penulis dan juga penjelasan laporan skripsi telah diuraikan mengenai "Analisa metode Weigthed Sum Model (WSM) pada sistem pendukung keputusan untuk menentukan siswa pemegang Kartu Indonesia Pintar (KIP)"

1. Dari sistem pendukung keputusan ini pengguna bisa menentukan siswa pemegang Kartu Indonesia Pintar (KIP) tersebut berdasarkan nilai referensi akhir, dimana apabila nilai referensi semakin besar, maka untuk menetukan siswa pemegang Kartu Indonesia Pintar (KIP) semakin layak dan jika nilai referensi semakin kecil, maka untuk menetukan siswa pemegang Kartu Indonesia Pintar (KIP) SD Negeri 091329 tersebut tidak layak.

2. Data yang digunakan pada penelitian ini adalah data siswa yang memiliki Kartu Perlindungan Sosial.

3. Sistem pendukung keputusan untuk menentukan siswa pemegang Kartu Indonesia Pintar (KIP) ini sudah bersifat dinamis, sehingga subkriteria bisa diperbaharui (update dengan mudah).

4. Hasil akhir yang diperoleh dari sistem pendukung keputusan ini akan memberikan suatu alternatif, untuk menentukan siswa pemegang Kartu Indonesia Pintar (KIP).

\section{REFERENCES}

[1] Solikhun, "PERBANDINGAN METODE WEIGHTED PRODUCT DAN WEIGHTED SUM MODEL DALAM PEMILIHAN PERGURUAN SWASTA TERBAIK JURUSAN,” Kumpul. J. ilmu Komput., vol. 04, no. 01, pp. 70-87, 2017.

[2] A. Mesran, Suginam, Surya Darma Nasution, "PENERAPAN WEIGHTED SUM MODEL ( WSM ) DALAM PENENTUAN PESERTA JAMINAN,” J. Ris. Sist. Inf. dan Tek. Inform., no. 1, pp. 40-47, 2017.

[3] S. R. Ningsih, I. S. Damanik, I. Gunawan, and W. Saputra, "ELECTRE DALAM MENENTUKAN PENERIMA PROGRAM INDONESIA PINTAR ( PIP ) MELALUI KARTU INDONESIA PINTAR ( KIP ) ( STUDI KASUS : SD SWASTA AL - WASHLIYAH MOHO KABUPATEN SIMALUNGUN ),” vol. I, pp. 264-275, 2017. 